UCRL-JC- 120317

PREPRINT

\title{
ELECTROCHEMICAL BEHAVIOR OF CARBON AEROGELS DERIVED FROM DIFEERENT PRECURSORS
}

\author{
R: W: Pekala \\ C. T. Alviso \\ J. K. Nielsen \\ T. D. Tran \\ G. M. Reynolds \\ M. S. Dresshaus
}

This paper was prepared for submittal to

MRS 1995 Spring Meeting

San Francisco, CA

April 17-21, 1995

\section{RECEIVED}

NOV 171995

O.S.I

April 1995

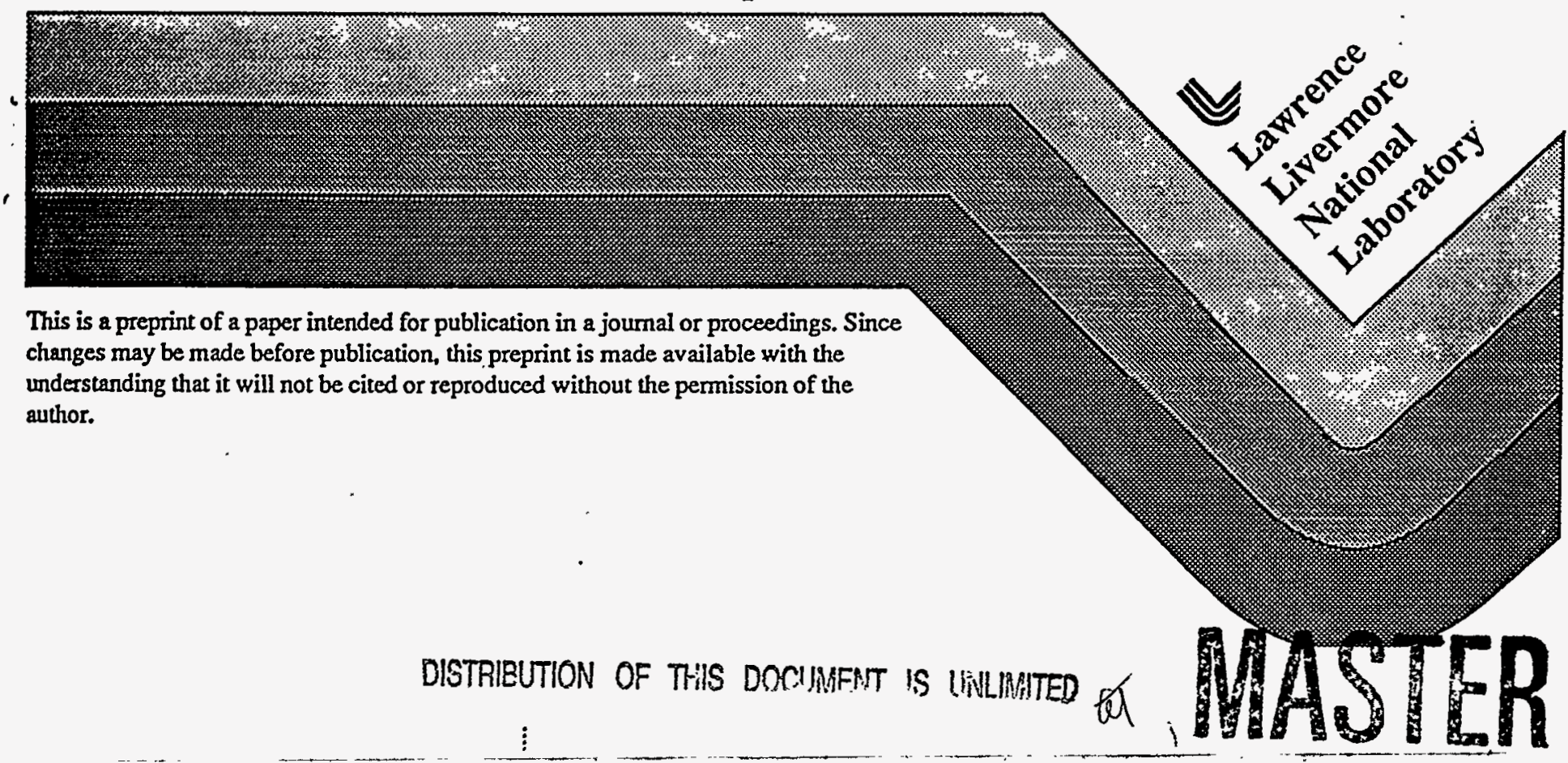


This document was prepared as an account of work sponsored by an agency of $\therefore$. S United States Government. Neither the United States Government nor the a. University of California nor any of their employees, makes any warranty, express or implied, or assumes any legal liability or responsibility for the accuracy, 74 is is compléteness, or usefulness of any information, apparatus, product, or process "disclosed, or represents that its use would not infringe privately owned rights. Reference herein to any specific commercial product, process, or service by trade if 1 -name, trademark, manufacturer, or otherwise, does not necessarily constitute or i. imply its endorsement, recommendation, or favoring by the United States Government or the University of California. The views and opinions of authors expressed herein do not necessarily state or reflect those of the United States Government or the University of California, and shall not be used for advertising or product endorsement purposes. 


\author{
R.W. PEKALA, C.T. ALVISO, J.K. NIELSEN, T.D. TRAN \\ G.A.M. REYNOLDS*, AND M.S. DRESSELHAUS* \\ Chemistry \& Materials Science Department \\ Lawrence Livermore National Laboratory \\ Livermore, CA 94550 \\ *Department of Physics \\ Massachusetts Institute of Technology \\ Cambridge, MA 02139
}

\begin{abstract}
The ability to tailor the structure and properties of porous carbons has led to their increased use as electrodes in energy storage devices. Our research focuses on the synthesis and characterization of carbon aerogels for use in electrochemical double layer capacitors. Carbon aerogels are formed from the sol-gel polymerization of (1) resorcinol-formaldehyde or (2) phenolic-furfural, followed by supercritical drying from carbon dioxide, and subsequent pyrolysis in an inert atmosphere. These materials can be produced as monoliths, composites, thin films, powders, or microspheres. In all cases, the areogels have an open-cell structure with an ultrafine pore size $(<100 \mathrm{~nm})$, high surface area $\left(400-1100 \mathrm{~m}^{2} / \mathrm{g}\right)$, and a solid matrix composed of interconnected particles, fibers, or platelets with characteristic dimensions of $10 \mathrm{~nm}$. This paper examines the effects of the carbon precursor and processing conditions on electrochemical performance in aqueous and organic electrolytes.
\end{abstract}




\section{INTRODUCTION}

The nanoengineering of materials is an area of intensive research because small clusters of atoms $(1-100 \mathrm{~nm})$ provide large interfacial areas and properties that range from the molecular to - the bulk solid-state limits. Aerogels have a unique morphology in that both the covalentlybonded particles of the solid phase and the interconnected pores of the gas phase have nanometer-sized dimensions. This structure leads to extremely high surface areas (400-1100 $\mathrm{m}^{2} / \mathrm{g}$ ) with a large fraction of the atoms covering the surface of the interconnected particles. Solgel polymerization conditions can be used to engineer the particle size, particle interconnectivity, and pore size in these materials.

The polycondensation of (1) melamine with formaldehyde, (2) resorcinol with formaldehyde, and (3) phenolic with furfural are three proven synthetic routes for the formation of organic aerogels. The latter two materials can also be pyrolyzed in an inert atmosphere to give carbon aerogels [1-5]. Carbon aerogels are the first electrically conductive aerogels to be synthesized, and they are finding applications as electrodes in double layer capacitors used for energy storage or capacitive deionization [6-9]. In this paper, we discuss the chemistry-structure-property relationships of carbon aerogels derived from different polymeric precursors.

\section{EXPERIMENTAL}

The preparation of resorcinol-formaldehyde (RF) aerogels and their carbonized derivatives has been described elsewhere [4]. Briefly, resorcinol (1,3 dihydroxybenzene) and formaldehyde were mixed in a 1:2 molar ratio, respectively. Deionized/distilled water was added as the diluent and sodium carbonate as the base catalyst. After stirring to form a homogeneous solution, the mixture was poured into glass vials, sealed, and cured at elevated temperature $\left(50-85^{\circ} \mathrm{C}\right)$. Upon completion of the cure cycle, the crosslinked gels were exchanged with acetone and subsequently dried from supercritical carbon dioxide $\left(\mathrm{T}_{\mathrm{c}}=31^{\circ} \mathrm{C} ; \mathrm{P}_{\mathrm{c}}=7.4 \mathrm{MPa}\right)$. This procedure resulted in the formation of monolithic RF aerogels which were subsequently pyrolyzed $\left(600-1100^{\circ} \mathrm{C}\right)$ in flowing nitrogen to form carbon aerogels.

Phenolic-furfural (PF) gels were prepared from a commercially available polymer solution (FurCarb UP520; QO Chemicals, Inc., West Lafayette, IN) [5]. This solution was composed of approximately a 50:50 mixture of a phenolic novolak resin dissolved in furfural. The Furcarb UP520 was diluted with 1-propanol and 10 parts per hundred resin catalyst (a mixture of aromatic acid chlorides; Q2001; QO Chemicals, Inc., West Lafayette, IN) was added. Solutions prepared with different amounts of diluent were then poured into glass vials, sealed, and cured for 7 days at $85^{\circ} \mathrm{C}$. A small amount of syneresis was observed during the cure cycle, allowing the gels to be-easily removed. PF gels were supercritcally dried and pyrolyzed in the same manner as RF gels.

A variety of characterization techniques were used to analyze the carbon aerogels. Particle size and surface area were evaluated with transmission electron microscopy and gas adsorption techniques. Raman spectroscopy measurements were obtained in a backscattering configuration 
using a 488-nm excitation. Transverse magnetic susceptibility measurements were carried out in a Superconducting Quantum Interference Design (SQUID) magnetometer. Samples were mounted in drinking straws and scanned in a 1-T field in a temperature range of 4-300 K.

Electrochemical studies were performed using a 64-channel Maccor battery tester. Experiments were done using circular $\left(4.5 \mathrm{~cm}\right.$-diameter) Teflon ${ }^{\circledR}$ cells. Two identical $(1.5 \mathrm{~cm}$ diameter, $1 \mathrm{~mm}$ thick) carbon electrodes were used in the cell and separated by 2 pieces of Whatman fiberglass filter paper (934-AH). Nickel foils were used as current collectors in aqueous cells, while aluminum foils were used as current collectors in cells with organic electrolytes. The whole assembly was sandwiched between 2 Teflon ${ }^{\circledR}$ plates and held together by $0.6 \mathrm{~cm}$-diameter Teflon ${ }^{\circledR}$ screws. The aqueous electrolyte was $5 \mathrm{M} \mathrm{KOH}$. The organic electrolyte was $0.5 \mathrm{M}$ tetraethylammonium tetrafluoroborate $\left(\mathrm{Et}_{4} \mathrm{NBF}_{4}\right.$, Aldrich) in propylene carbonate. The operating voltage for the aqueous cell was $1 \mathrm{~V}$ per cell and that for the organic electrolyte was $3 \mathrm{~V}$. The testing of aqueous cells was carried out under ambient conditions. The experiments with organic electrolytes were performed in a dry argon-atmosphere glove box ( $<6 \mathrm{ppm}$ water) at $16 \pm 2^{\circ} \mathrm{C}$. The charge/discharge current was $14 \mathrm{~mA} / \mathrm{cm}^{2}$ (geometric).

\section{RESULTS AND DISCUSSION}

The chemistry of resorcinol-formaldehyde(RF) and phenolic-furfural $(\mathrm{PF})$ aerogels has been discussed previously $[4,5]$. Both reactions result in highly crosslinked gels that have an aromatic backbone. The $\mathrm{RF}$ aerogels lose $\sim 50 \%$ of their starting mass upon carbonization at $1050{ }^{\circ} \mathrm{C}$ whereas the $\mathrm{PF}$ aerogels lose $\sim 45 \%$. Volumetric shrinkage in both cases can range from $60-75 \%$, depending upon the exact formulation. Both precursors are considered to be non-graphitizable.

The structure and properties of RF-derived carbon aerogels are largely controlled by the [Resorcinol]/[Catalyst] $(\mathrm{R} / \mathrm{C})$ ratio of the starting solution. At $\mathrm{R} / \mathrm{C}=50$, carbon aerogels have particle diameters on the order of 7-9 $\mathrm{nm}$ with specific surface areas of $\sim 800 \mathrm{~m}^{2} / \mathrm{g}$. In this type of aerogel, the particles are well-interconnected with the neck size approaching the particle diameter. In contrast, carbon aerogels synthesized at $R / C=200$, have lower surface areas $(\sim 600$ $\mathrm{m}^{2} / \mathrm{g}$ ) and smaller necks between spherical particles of $\sim 12 \mathrm{~nm}$ diameter. These structures have been explained in terms of the initial sol-gel chemistry and solution thermodynamics $[10,11]$. Interestingly, the specific surface area of these carbon aerogels is practically independent of the bulk density for samples prepared at the same $R / C$ ratio. Thus, $\mathrm{RF}$-derived carbon aerogels with a higher bulk density simply have more interconnected particles per unit volume than their low density counterparts.

In the case of the PF-derived carbon aerogels, transmission electron microscopy revealed interconnected platelets of irregular shape with characteristic sizes of 10-15 $\mathrm{nm}$. The specific surface area of this material was also found to be largely independent of density at a given catalyst level. Figure 1 shows the specific surface area of RF aerogels, PF aerogels, and their carbonized derivatives as a function of density. 


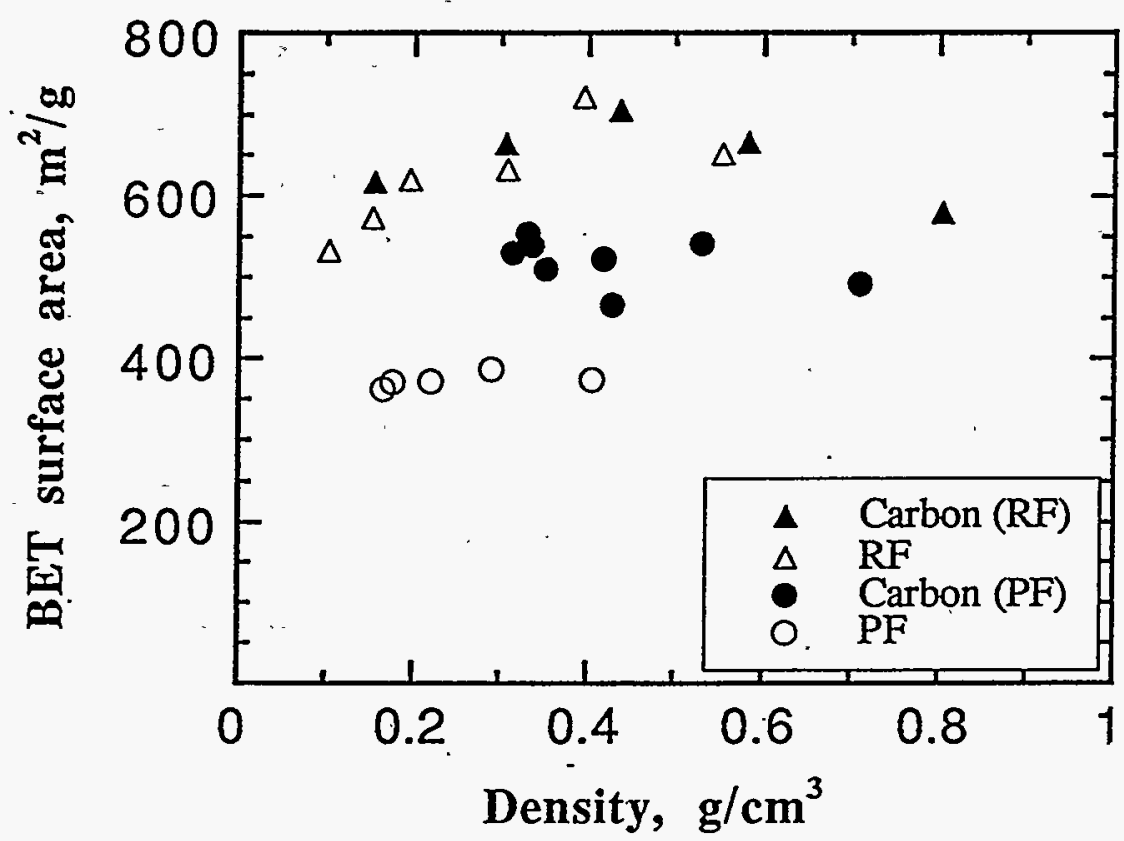

Figure 1. A comparison of the specific surface area of resorcinol-formaldehyde (RF) aerogels, phenolic-furfural (PF) aerogels, and their carbonized derivatives.

Raman spectroscopy was performed on carbon aerogels to probe the internal structure of the interconnected particles or platelets $[12,13]$. In both cases, a Raman-allowed $\mathrm{E}_{2 \mathrm{~g} 2}$ peak was observed near $1580 \mathrm{~cm}^{-1}$ (designated as the $G$ band) while a Raman line attributable to in-plane disorder was observed near $1360 \mathrm{~cm}^{-1}$ (the $D$ band). The in-plane microcrystallite size $\mathrm{L}_{a}$ was estimated from Knight's empirical formula, $\mathrm{L}_{a}=44\left(\mathrm{I}_{G} / \mathrm{I}_{D}\right)$. For RF-based carbon aerogels pyrolyzed at $1050^{\circ} \mathrm{C}, \mathrm{L}_{a}$ is approximately $25 \AA$, independent of the bulk density or R/C ratio. For $\mathrm{PF}$-based carbon aerogels pyrolyzed under the same conditions, $\mathrm{L}_{a}$ ranges from $25-35 \AA$ with a slight density dependence. In both cases, the Raman data reveal that 25-35 $\AA$ wide graphene sheets are the underlying units in the carbon aerogel structure. The convoluted connection of the graphene sheet segments and the presence of defect sites are responsible for the micropores $(<2$ $\mathrm{nm}$ ) within the individual particles or platelets.

Magnetic susceptibility measurements were performed on carbon aerogels from $4-300 \mathrm{~K}$ as a function of bulk density and polymerization conditions [12,13]. In the low temperature regime, Curie-like behavior was observed and the number of spins per gram was determined for each specimen. Generally, carbon aerogels synthesized at $\mathrm{R} / \mathrm{C}=50$ exhibited a stronger temperature dependence at low temperature, and hence a larger number of unpaired spins per gram than their $\mathrm{R} / \mathrm{C}=200$ and $\mathrm{R} / \mathrm{C}=300$ counterparts at the same sample density. These data corroborate the $\mathrm{BET}$ surface area measurements and suggest that the $\mathrm{R} / \mathrm{C}=50$ samples are more highly disordered. Preliminary data on PF-based carbon aerogels show 2-3 times more spins per gram than RF- 
based carbon aerogels $(\mathrm{R} / \mathrm{C}=200)$ even though the BET surface areas exhibit the opposite trend. This discrepancy is under further investigation.

Because RF-derived and PF-derived carbon aerogels have high specific surface areas, they are potentially attractive as electrodes in double layer capacitors. Figure 2(a) shows the specific capacitance of the carbon aerogels in 5M KOH. The RF-derived carbon aerogels exhibit larger capacitance values than the PF-derived carbon aerogels at all densities. As expected, the specific capacitance of the RF-derived carbon aerogels depends upon the R/C ratio. At a fixed density, the following trend is observed for the specific capacitance: $R / C=50>R / C=200>R / C=300$. 

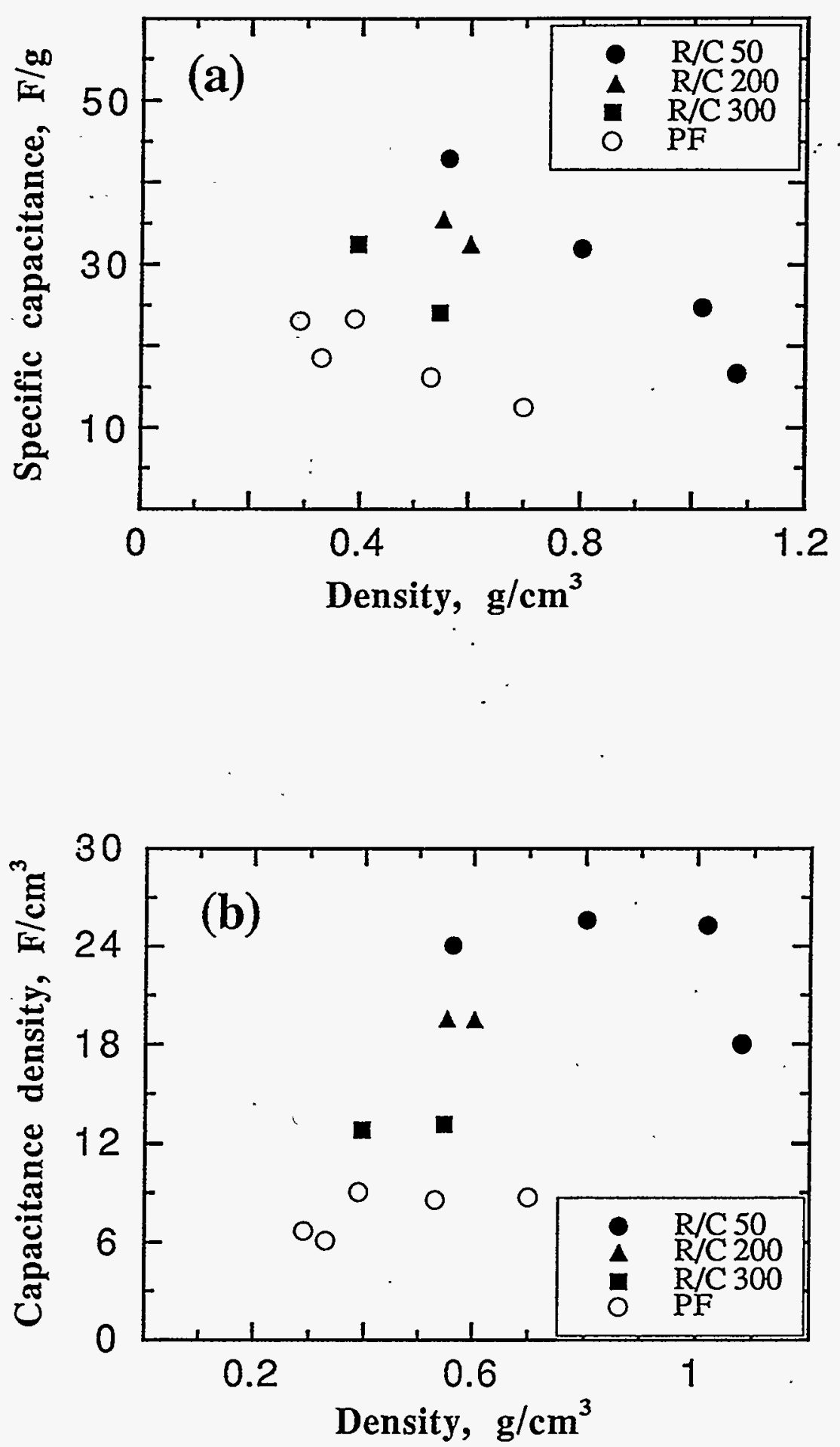

Figure 2. A plot of (a) specific capacitance vs. bulk density and (b) capacitance density vs. bulk density for carbon aerogels tested in $5 \mathrm{M} \mathrm{KOH}$. 

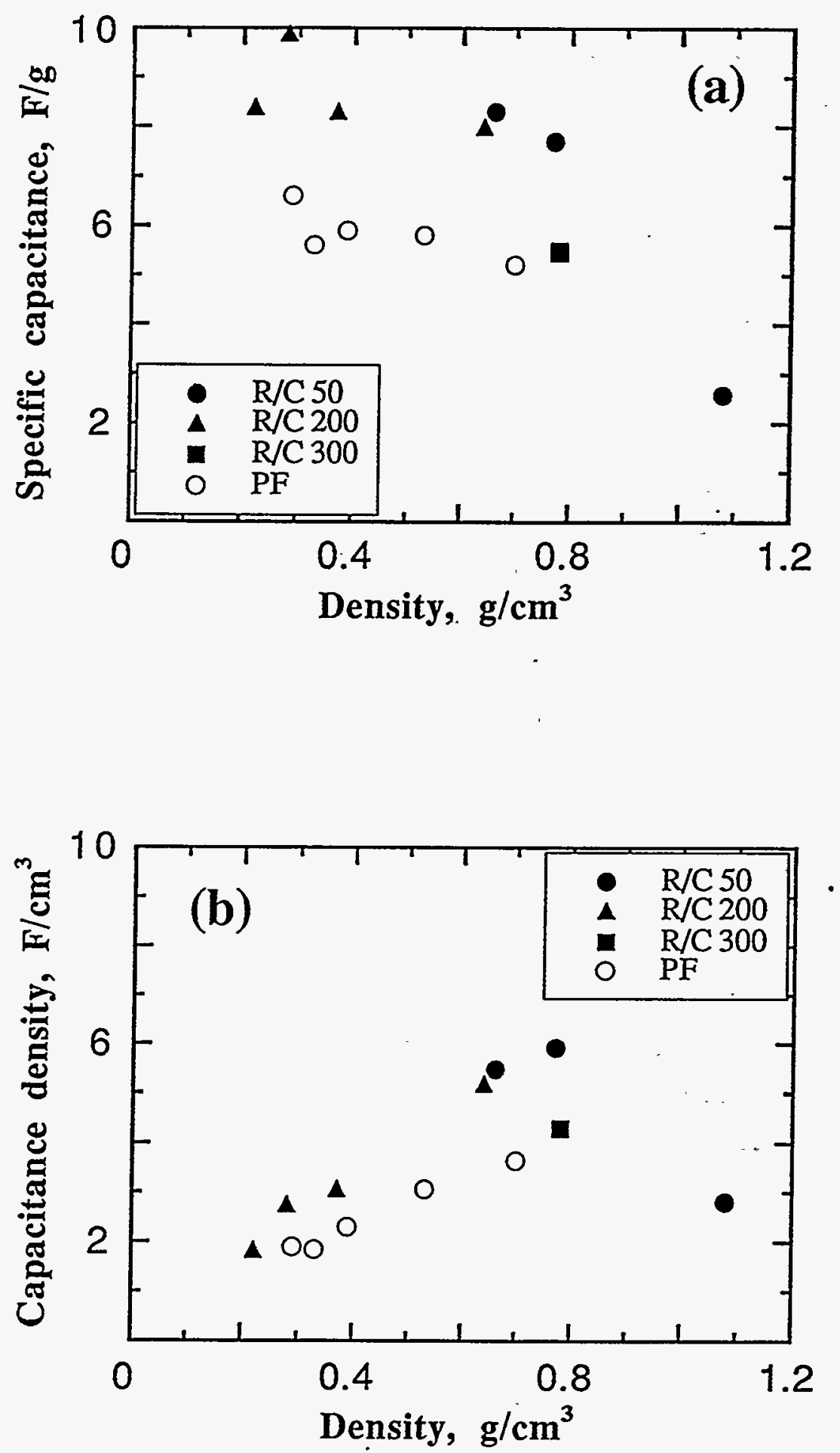

Figure 3. A plot of (a) specific capacitance vs. bulk density and (b) capacitance density vs. bulk density for carbon aerogels tested in $0.5 \mathrm{M} \mathrm{Et}_{4} \mathrm{NBF}_{4} /$ propylene carbonate. 
The above data are in accord with the BET surface area.measurements. In all cases, the specific capacitance decreases with increasing density of carbon aerogels. This effect can be explained in terms of the increased interconnectivity (particle coordination number) of the high density samples. The increased contacts lead to less accessible surface area per interconnected particle or per gram of carbon.

Figure 2(b) shows the capacitance density $\left(\mathrm{F} / \mathrm{cm}^{3}\right)$ as a function of bulk density for the carbon aerogels derived from different precursors. There is a linear increase in capacitance density from $0-0.5 \mathrm{~g} / \mathrm{cm}^{3}$, followed by a plateau region in which maximum capacitance values of $\sim 27 \mathrm{~F} / \mathrm{cm}^{3}$ and $\sim 9 \mathrm{~F} / \mathrm{cm}^{3}$ are observed for the RF- and PF-derived carbon aerogels, respectively. Our data also show that the capacitance decreases at very high densities, suggesting that the average pore size is becoming too small for double layer formation. Based upon permeability data, the RF-derived carbon aerogels have an average mesopore size of $\sim 3.5 \mathrm{~nm}$ at $1.1 \mathrm{~g} / \mathrm{cm}^{3}$.

Figures 3(a) and 3(b) show the specific capacitance and capacitance density of carbon aerogels in the organic electrolyte. The trends are similar to the aqueous case, although the magnititude of the capacitance is 3-4 times lower. A sharp decrease in capacitance density is also observed for the highest density specimen, suggesting that the pore size is becoming too small to accomodate the double layer. The energy density $\mathrm{E}$ of an individual cell can be calculated as follows

$$
\mathrm{E}=0.5 \mathrm{CV}^{2}
$$

where $\mathrm{C}$ equals capacitance and $\mathrm{V}$ equals operational voltage. In the case of the organic electrolyte, a nine-fold increase in energy density might be expected because of the higher cell voltage in comparison to the aqueous case ( $3 \mathrm{~V}$ vs. $1 \mathrm{~V}$ ). The increased energy density, however, is only 2-3 times the aqueous case because of the decreased capacitance associated with the larger ionic species and the loyer dielectric constant of the organic electrolyte.

\section{SUMMARY}

Carbon aerogels can be synthesized from different polymeric precursors to give porous electrodes with low electrical resistivity, controllable pore size, and high surface area. RFderived carbon aerogels provide higher capacitance than PF-derived carbon aerogels in both aqueous and organic electrolytes. Maximum values of $\sim 27 \mathrm{~F} / \mathrm{cm}^{3}$ and $\sim 6 \mathrm{~F} / \mathrm{cm}^{3}$ were achieved in these respective electrolytes.

\section{ACKNOWLEDGMENT}

This work was performed under the auspices of the U.S. Department of Energy by Lawrence Livermore National Laboratory under contract \#W-7405-ENG-48 with financial support from the Office of Basic Energy Sciences - Division of Advanced Energy Projects. 


\section{REFERENCES}

[1] R.W. Pekala and F.M. Kong, Polym. Prpts., 30(1), 221 (1989).

[2] R.W. Pekala, C.T. Alviso, and J.D. LeMay, in Chemical Processing of Advanced Materials, L.L. Hench and J.K. West, eds., (New York: John Wiley \& Sons, Inc., 1992), pp. 671-683.

[3] R.W. Pekala, C.T. Alviso, F.M. Kong, and S.S. Hulsey, J. Non-Cryst. Solids, 145, 90 (1992).

[4] R.W. Pekala and C.T. Alviso, in Novel Forms of Carbon, C.L. Renschler, J.J. Pouch, and D.M Cox, eds., MRS Symp. Proc. 270,3 (1992).

[5] R.W. Pekala, C.T. Alviso, X. Lu, J. Groß, and J. Fricke, J. Non-Crystalline Solids, in press.

[6] S.T. Mayer, R.W. Pekala, and J.L. Kaschmitter, in Proc. of 2nd Int'l Seminar on Double Layer Capacitors and Similar Energy Storage Devices, S.P. Wolsky and N. Marincic, eds., (Boca Raton: Florida Educational Seminars, 1992).

[7] S.T. Mayer, R.W. Pekala, and J.L. Kaschmitter, J. Electrochem. Soc., 140(2), 446 (1993).

[8] R.W. Pekala, S.T. Mayer, J.F. Poco, and J.L. Kaschmitter, in Novel Forms of Carbon II, C.L. Renschler, D.M. Cox, J.J. Pouch, and Y. Achiba, eds., MRS Symp. Proc. 349, 79 (1994).

[9] J.C. Farmer, D.V. Fix, G.V. Mack, R.W. Pekala, and J.F. Poco, in Proc. of Int'l Low Level Waste Conference (Orlando, FL July 10-12, 1995); in press.

[10] R.W. Pekala and D.W. Schaefer, Macromolecules, 26(20), 5487 (1993).

[11] M.S. Gebert and R.W. Pekala, Chem. Mater., 6(2), 220 (1994).

[12] A.W.P. Fung, Z.H. Wang, K. Lu, M.S. Dresselhaus, and R.W.Pekala, J. Mat. Res., 1875 (1993).

[13] G.A.M. Reynolds, A.W.P. Fung, Z.H. Wang, M.S. Dresselhaus, and R.W. Pekala, Phys. Rev. B, 50(24), 18590 (1994). 



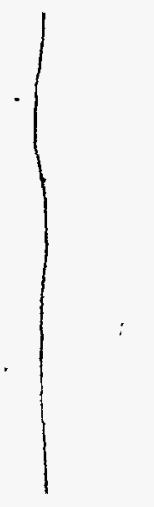


.
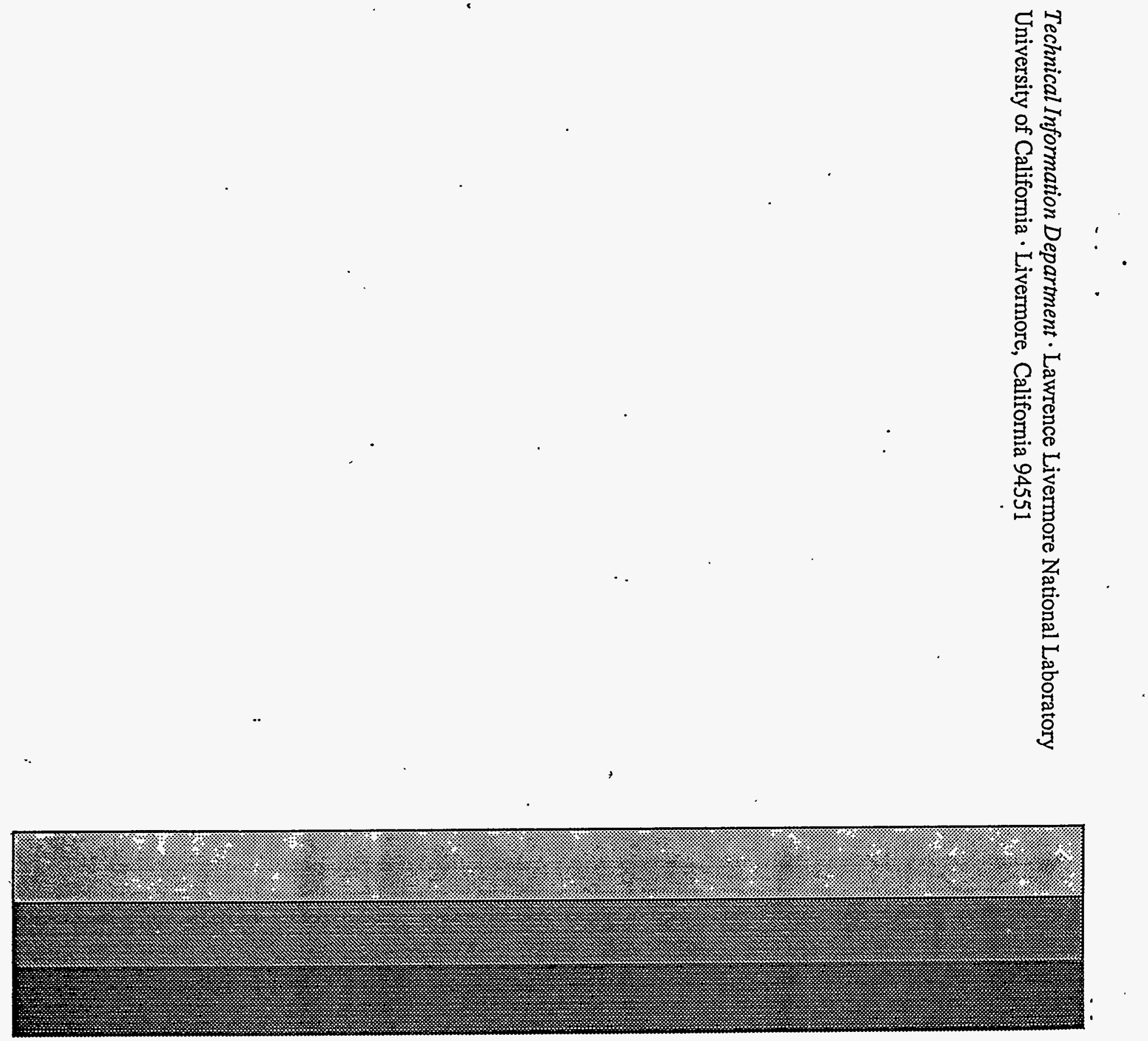